\title{
EI GOBIERNO DE LA MORAL Y LA SALUD: EDUCACIÓN ALIMENTARIA EN EL DISCURSO PEDAGÓGICO
}

\author{
Ângela Aisenstein \\ Universidad de San Andrés e \\ Univesidad Nacional de Luján, Argentina. \\ Maria Eugenia Cairo \\ Universidad de San Andrés, Argentina.
}

$\cos 8$

\section{O GOVERNO DA MORAL E SAÚDE: EDUCAÇÃO ALIMENTAR NO DISCURSO PEDAGÓGICO}

\begin{abstract}
Resumo
Estudos epidemiológicos produzidos na última década destacam a subnutrição como uma das doenças do novo século. Para tratar e prevenir estas problemáticas, os Estados e instituições da sociedade civil desenharam diferentes tipos de intervenção voltadas para regular o regime alimentar da população. Estas questões não são novas. Na Argentina, desde as últimas décadas do século 19 e primeiras do século 20, parte do discurso pedagógico voltou-se para ensinar os alunos e alunas da escola primária o quê, quanto e como comer. Tomando como fontes duas revistas pedagógicas oficiais, este trabalho examina as concepções e práticas sobre o tema que se articularam no discurso pedagógico estatal e as ações por meio das quais se difundiram na Argentina.

Palavras-chave: discurso, saúde, moral, dietética, escola.
\end{abstract}

\section{GOVERNMENT OF THE MORAL AND THE HEALTH: ALIMENTARY EDUCATION IN PEDAGOGICAL DISCOURSE}

\section{Abstract}

Over the past decade, epidemiological studies highlight malnutrition as one of the diseases of the century. To address and prevent these problems States and civil society institutions design different types of interventions to regulate the intake of food of the population. These issues are not new. Since the last decades of the 19th and early 20th century in Argentina, a part of the pedagogic discourse has been aimed at teaching children attending primary school what, how much and how to eat. This work, paper, article explores the concepts and practices on the subject 
that were articulated in the state pedagogic discourse and the actions through which they were spread in Argentina. Two official pedagogical journals are used as sources of research.

Key-words: discourse, health, moral, dietetic, school.

\section{EI GOBIERNO DE LA MORAL Y LA SALUD: EDUCACIÓN ALIMENTARIA EN EL DISCURSO PEDAGÓGICO}

\section{Resumen}

Estudios epidemiológicos de la última década destacan a la malnutrición como una de las enfermedades del nuevo siglo. Para atender y prevenir estas problemáticas los Estados e instituciones de la sociedad civil diseñan distintos tipos de intervenciones para regular el régimen de ingesta de la población. Estas cuestiones no son nuevas. En Argentina ya desde las últimas décadas del siglo 19 y primeras del 20 parte del discurso pedagógico se orientó a enseñar a los niños y las niñas que asistían a la escuela primaria qué, cuánto y cómo comer. Este trabajo indaga las concepciones y prácticas sobre el tema que se articularon en el discurso pedagógico estatal y las acciones a través de las cuales se difundieron en Argentina. Se toman como fuentes dos revistas pedagógicas oficiales.

Palabras-clave: discurso, salud, moral, dietética, escuela.

\section{LE GOUVERNEMENT DE LA MORAL ET DE LA SANTÉ: L'EDUCATION ALIMENTAIRE DANS LE DISCOURS PÉDAGOGIQUE}

\section{Résume}

Des études épidémiologiques de la dernière décennie comprennent la malnutrition comme l'une des maladies du nouveau siècle. Pour traiter et prévenir ces problèmes, les États et les institutions de la société civile conçu différents types d'interventions visant à réglementer le régime de la population. Ces questions ne sont pas nouvelles. En Argentine depuis la dernière décennies du $19 \mathrm{e}$ siècle et la première partie du $20 \mathrm{e}$ du discours pédagogique de l'État a été orienté pour enseigner aux enfants qui fréquentent l'école primaire, combien et comment manger. Ce travail explore les idées et les pratiques sur le sujet qui est énoncé dans les discours pédagogique et les actions qui ont été diffusées à l'Argentine. Deux revues pédagogiques officielles sont considérées comme des sources.

Mots-clé: discours, santé, moral, diététique, école.

EAN ${ }^{1}$ es cualquier conjunto de experiencias educativas diseñadas para facilitar la adopción voluntaria de hábitos alimentarios saludables y otros comportamientos relacionados con la nutrición que conduzcan a la salud y al bienestar general'. Esta definición sugiere que el cambio de hábito o conducta es el criterio adecuado para evaluar la efectividad de una intervención educativa. (Pueyrredón, 2009) ${ }^{2}$

\footnotetext{
${ }^{1}$ Educación Alimentaria Nutricional

${ }^{2}$ Pueyrredón, P. Revisión de evaluaciones de intervenciones de educación alimentaria nutricional. Resumen de artículo publicado por el Journal of Nutrition Education and Behaviour. http://files.cloudpier.net/cesni/biblioteca/0ac62105a73d4994173d0000.pdf. Consulta: 26 jan. 2011.
} 
$\mathrm{D}$ iversos estudios epidemiológicos realizados en la última década en distintos contextos geográficos destacan a la malnutrición, concepto que contiene tanto a la obesidad como a la desnutrición, como una de las enfermedades del nuevo siglo. Diseñados desde el paradigma biomédico, estos estudios definen ciertos problemas alimentarios derivándolos de cuestiones socioeconómicas y culturales como causas predisponentes de una serie de enfermedades no trasmisibles, denominadas crónico-degenerativas ${ }^{3}$ que en los últimos años han aumentado los gastos nacionales y globales en salud.

Para atender y prevenir estas problemáticas los Estados junto con instituciones de la sociedad civil diseñan distinto tipo de intervenciones, muchas de ellas educativas ${ }^{4}$, con la finalidad de regular el régimen de ingesta de la población ${ }^{5}$. Los Ministerios de Educación, entre otros organismos, se hacen presente en la concreción de las políticas de alimentación, al agenciar la implementación de medidas, preparando material educativo, incentivando prácticas alimentarias y nutricionales saludables junto a los alumnos (Richter y Fernández Vaz, 2008).

Estas estrategias buscan reforzar las resistencias de los cuerpos, protegerlos contra las enfermedades infecciosas, combatir la obesidad, la diabetes, la desnutrición y otros males que asolan la población, intentando garantizar la oferta de alimentos adecuados a la nutrición. El hilo conductor de dichas políticas es el derecho humano a la alimentación y la seguridad alimentaria y nutricional (Richter y Fernández Vaz, 2008).

Entender estas estrategias de política educativa y ponderar sus alcances y limitaciones exige poner el problema o tema de la alimentación dentro de la perspectiva social y cultural. Este marco permite señalar que los conceptos, ideas y prácticas actuales se construyen en un proceso social que no pueden ignorarse (Douglas, 1998). Todos los humanos de todas las culturas adoptan un conjunto de creencias y actitudes culturalmente construidas en relación a los objetos del mundo, entre los que se encuentra la alimentación.

El hombre, dotado de pensamiento conceptual, posee un lenguaje que le permite evaluar y transmitir la experiencia pasada. Sus impulsos fundamentales, por ejemplo el hambre, son remodelados desde su nacimiento por un conjunto de técnicas, reglas y

${ }^{3}$ CESNI (2009), Indec: Encuesta Nacional de Factores de Riesgo (2005) tales como diabetes, colesterol, cardiopatías, cáncer.

${ }^{4}$ Ver Journal of School Health. October 2010, v. 80, n. 10; Journal of School Health. October 2009, v. 79, n. 10; Journal of School Health. may 2008, v. 78, n. 5; y Annals of the American Academiy of Political and Social Sciences, v. 615, Jan 2008.

${ }^{5}$ Siguiendo a Turner (1982) régimen, en tanto término médico alude a todo sistema de terapia prescripto, especialmente una dieta regular; sin embargo puede también portar el significado antiguo de sistema de gobierno y en este caso será legítimamente extendido para incluir la idea de gobierno del cuerpo. 
símbolos que se le transmiten de generación en generación. La pauta de comportamiento resultante se llama cultura y se personifica en un grupo de individuos cuyas relaciones mutuas y entorno natural están reguladas por un sistema de reglas que encuentra su expresión dentro de dicha cultura (de Garine, 1995).

Como señala Messer (1995), volviendo extraño lo familiar, posiblemente a excepción de la moderna sociedad occidental, no hay ningún grupo cultural que evalúe los alimentos individuales que ingiere y sus combinaciones usando categorías científicas tales como energía, grasas, proteínas, vitaminas y minerales. Para comprender las presiones que favorecen o favorecieron el surgimiento y las persistencia de tales reglas $y$ comportamientos, se necesita información sobre la historia subyacente a estas creencias y prácticas particulares y sobre los movimientos y mezclas de poblaciones y otras unidades socioculturales que las mantuvieron y las hicieron posible (Messer, 1995).

En lo que se refiere a la historia de la educación, al menos en occidente, las estrategias de elaboración y difusión de reglas de comportamiento alimentario no son una novedad. Para el caso argentino entre las últimas décadas del siglo 19 y primeras del 20, y a través de definiciones científicas, recomendaciones sanitarias y morales y distribuciones de roles en clave de género, parte del discurso pedagógico se orientó a enseñar a los niños y las niñas que asistían a la escuela primaria qué, cuánto y cómo comer.

De ese modo una actividad del orden de lo primario y básico para la supervivencia individual y el orden de los grupos sociales (Douglas, 1973) pasaría a formar parte de los modos de educación escolar del cuerpo y de la sensibilidad de la mano de las asignaturas escolares, las disposiciones espaciales y la organización del horario y el calendario escolar. A la vez, junto a los intentos por ordenar el régimen de ingesta de la población las indicaciones sobre los alimentos, en sentido amplio, influiría en el modelado de un orden familiar y social necesario para el desarrollo de una sociedad moderna e industriosa.

Este trabajo es un avance de un estudio que indaga las concepciones, valores y prácticas sobre el tema que se articularon en el discurso pedagógico estatal y las acciones a través de las cuales se difundieron algunos juicios de producción y consumo alimentarios (Bourdieu, 1988) y prescripciones sobre roles sociales atribuidos a hombres y mujeres (Nari, 2004) en Argentina desde fines del siglo 19 y primeras décadas del 20. 
Para ello se tomaron como fuentes El Monitor de la Educación Común y la Revista de Educación. ${ }^{6}$

\section{Decisiones metodológicas}

La historia del discurso pedagógico en relación a la alimentación puede ser relevada a través de diversas fuentes. En este trabajo se eligen dos revistas educacionales. Éstas resultan fuentes válidas de indagación historiográfica en tanto creación textual o forma narrativa, y como tales facilitan la expresión de la representación de la sociedad imaginada. A su vez, adquieren especial relevancia en este período histórico en particular ya que fueron un medio de divulgación privilegiado debido a las limitaciones del mercado editorial, la existencia de pocas bibliotecas y las escasas posibilidades de los maestros para acceder a los libros (Giovine et al, 2007).

La Revista de Educación de la Provincia de Buenos Aires resulta pertinente para indagar el tema ya que se constituyó en el origen de la prensa pedagógica de Argentina e, incluso, de Sudamérica (Diker, 2005, en Giovine et al, 2007). Por otro lado, en tanto órgano de expresión del Consejo General de Educación destinada a los miembros de los organismos estatales (principalmente los maestros) -y junto a El Monitor de la Educación Común - sus artículos fueron caja de resonancia de debates e ideas en virtud de su periódica aparición.

En ambas publicaciones dos cuestiones resultan significativas. La primera se refiere a los actores que intervienen, los modos en que ponen en juego sus ideas y proyectos y las actividades que realizan desde las instancias de gobierno en el proceso de diseñar, organizar y difundir las políticas estatales en educación al interior del sistema educativo. La segunda se refiere a la multiplicidad de los conocimientos, valores y registros discursivos que se ponen en juego simultáneamente en torno a un tema, por ejemplo lo que debía ser enseñado a los niños y/o las niñas o la duración y organización del día escolar (Aisenstein, 2011).

\footnotetext{
${ }^{6}$ En adelante El Monitor, fue creado por el Consejo Nacional de Educación (CNE) en septiembre de 1881, durante la primera presidencia de Julio Argentino Roca, y continuó editándose hasta 1949. A partir de entonces volvió a editarse durante los siguientes períodos: 1959-1961; 1965-1976, 2000-2001 y 2004 a la actualidad. EI CNE era la oficina dependiente del Ministerio de Justicia e Instrucción Pública responsable de la educación primaria, y en algunas épocas también de la educación secundaria normal. La Revista de Educación de la Provincia de Buenos Aires (publicación oficial del Consejo General de Cultura y Educación y de la Dirección General de Escuelas de la provincia de Buenos Aires) fue fundada por Sarmiento durante la presidencia de J. Urquiza y la gobernación provincial de V. Alsina. El primer número se publicó en enero de 1858 y continuó su edición casi en forma ininterrumpida hasta 1992. Fue reeditada a partir del año 2005 extendiéndose su publicación aún en la actualidad. Si bien a lo largo de su existencia la revista ha cambiado su denominación en distintos períodos, nos referiremos a ella como Revista de Educación (en adelante La Revista), por ser el nombre que ha predominado en el lapso de tiempo considerado en este trabajo.
} 
La lectura de algunos antecedentes (Pineau, 1997; Schoo, 2009) ha sido sugerente para ampliar la indagación más allá de la identificación de regularidades o elementos comunes en los discursos pedagógicos que se registran en cada una de dichas publicaciones; es más han alentado a ponerlas en diálogo entre sí para indagar los consensos y diferencias respecto del tema educativo en general, y en este caso particular, entre las élites provinciales y nacionales.

Pineau (1997) sugiere cierta correspondencia entre los procesos educativos de la provincia de Buenos Aires y los nacionales. Según este autor los primeros podrían ser estimados como una especie de "laboratorio" donde las elites gobernantes de finales del siglo 19 experimentaron las políticas que serian llevadas posteriormente al ámbito nacional.

Para entender las posibles tensiones es necesario señalar, siguiendo a Schoo (2009, p. 32) que "hacia mitad del siglo 19 se desarrolló un proceso de sistematización de instituciones educativas (Ringer, 1992). Dicho proceso supuso la unificación en una administración central nacional y específicamente educacional de las instituciones de enseñanza pre-existentes como forma de articularlas en una secuencia y jerarquía determinadas (Archer, 1981; Viñao, 2001), disponiendo rangos de obligatoriedad que hicieron a la educación un 'asunto de Estado' (Tedesco, 1994; Narodowski, 1994; Oszlak, 1997)". En este marco se sancionan las leyes de educación que organizan el sistema educativo provincial y nacional moderno ${ }^{7}$.

\section{La educación alimentaria en contexto}

Un profundo cambio pedagógico y social acompañó el pasaje del siglo 19 al 20: la expansión del dispositivo escolar como forma educativa hegemónica. La mayoría de las naciones del mundo legisló su educación básica y la volvió obligatoria. Argentina no fue la excepción. El ilustrado siglo 18 comprendió la educación como fenómeno humano, motor del cambio social y de los procesos de superación o progreso individual y colectivo, y reafirmó a la infancia como período etario educativo por antonomasia (Pineau, 2001). Sobre este pensamiento avanzó la construcción de la escuela como forma educativa moderna por excelencia en el período que se analiza.

Su hegemonía se construye sobre la idea de la

\footnotetext{
${ }^{7}$ La Ley de Educación Común, n. 988, de la Provincia de Buenos Aires sancionada en el año 1875, organizó el sistema educativo provincial. La ley de Educación Común n. 1420, sancionada por el Congreso nacional organizó el sistema educativo nacional argentino; se aprobó el 8 de julio de 1884 luego de amplios debates, consagrando a la educación primaria como obligatoria, gratuita y neutral desde el punto de vista religioso. La ley n. 988 se considera como un antecedente de la ley nacional n. 1420 .
} 
necesidad de tenencia de un conjunto de saberes por parte de todos los integrantes de la comunidad para poder ser parte de ella, y propone al Estado - en su dimensión de garante de bienestar general y encarnación máxima y racional de lo social- como agente legitimado para producir dicha distribución. Las ecuaciones son Educación = Escuela y Sociedad = Estado, de forma tal que la enunciación fundante 'la educación es un proceso social' se desplaza a 'la escuela debe ser estatal. (Pineau, 2001, p. 48-49)

Resulta fundamental señalar que para el caso argentino la conformación del Estado nacional iba de la mano de la conformación de la sociedad nacional. En tanto base material de la nación, la población del territorio argentino fue receptora de sucesivas oleadas de inmigrantes que arribaron desde fines del siglo 19 hasta la primera guerra mundial; ellos serían los destinatarios principales de las políticas de homogeneización cultural implementadas a través de la escuela (Cucuzza, 2007).

En este contexto la escuela asumió el saber pedagógico como saber de gubernamentalidad (Foucault, 1989, en Pineau, 2001), en tanto forma de disciplina y gobierno de la población en general y de cada individuo en particular. La construcción del poder moderno implicó la construcción de saberes que permitieron coaccionar sobre el colectivo sin anular la actuación sobre cada uno de los individuos. En tanto espacio de educación total (Lerena, 1984, en Pineau, 2001) la escuela se constituyó en una institución donde la totalidad de los hechos que se desarrollaban eran educativos.

Todo lo que sucedía en las aulas, en los patios, en los comedores, en los pasillos, en los espacios de conducción, en los sanitarios, eran experiencias intrínsecamente educativas a las que sería sometidos los alumnos (Pineau, 2001). Diversos sectores de la sociedad y diversas culturas ${ }^{8}$ se irán pedagogizando "hay que cuidar a estas personas, decirles lo que tienen que hacer y darles reglas más precisas" (Narodowski, 1995, en Carusso y Dussel, 2000 p. 17).

La producción discursiva que de este proceso deriva y a su vez lo constituye irá dando lugar a la construcción de aquello que Bernstein denomina discurso pedagógico oficial (DPO). El mismo se irá instituyendo como práctica discursiva a través de la cual el

\footnotetext{
${ }^{8}$ El porcentaje promedio de extranjeros respecto de la población total del país era, para el periodo en cuestión, del $22,47 \%$. De los cuales, para el censo de 1914 el $2 \%$ provenía de país limítrofe y el $28 \%$ de otro país. (Fuente. Elaboración propia en base a Indec. Censos nacionales de población. Indicadores demográficos seleccionados para fechas censales. Total del país. Años 1869-2001). "En cuanto al país de origen de los extranjeros censados en 1869, si bien los había de casi todas las naciones europeas e incluso otras de Asia y África, los tres países mediterráneos Italia, España y Francia - y los limítrofes - Chile, Bolivia, Paraguay, Brasil y Uruguay - constituían el 85 por ciento del total". En el periodo 1869-1895 "los italianos representan algo más del 50 por ciento de la migración neta total ocurrida en el periodo, y junto a los españoles constituyen las nacionalidades dominantes de la migración. Entre los provenientes del resto de Europa, en este periodo predominan los rusos, austríacos y húngaros. En el periodo 18951914 disminuye bastante la proporción de italianos, y los españoles, con 41,2 por ciento, pasan a ser el grupo principal. Sumados a los italianos representan más de las tres cuartas partes del total de la migración del período. Entre los otros europeos sobresalen los rusos y los polacos. También alcanzan importancia numérica como grupo los sirios y armenios dentro de la categoría resto del mundo" (Rechini de Lattes y Lattes, 1975, p. 61/ 64/65).
} 
poder y el control del Estado tratarán de ejercerse (Bernstein y Díaz, 1984), y constituirá el intento estatal de llevar adelante el gobierno o conducción del naciente sistema educativo como parte del gobierno de las sociedades modernas.

Acorde a la diversificación de espacios, sectores y aspectos de la vida humana que se asumen como posibles de ser pedagogizados, el DPO irá incluyendo prescripciones para casi la totalidad del abanico de comportamientos de la vida humana. En este sentido supondrá el intento de modificar a los sujetos en una dirección determinada, estructurar la obediencia, configurar las moralidades, educar las conciencias y los cuerpos.

Profundizando en las ideas de Bernstein $(1984 ; 1998)$ la función básica de dicho discurso será el ejercicio del poder, esencialmente en la predeterminación discursiva de los patrones de conducta (reforzando las normas existentes, cambiando las normas viejas y produciendo nuevas normas), teniendo como objetivo colocar, fijar y orientar a los sujetos hacia posiciones deseadas (posiciones creadas y mantenidas por los principios dominantes) tanto como mantener el control legal y político sobre agentes, agencias, prácticas y discursos requeridos para la reproducción de la cultura y la producción de la conciencia. En este sentido se asociará con el carácter normativo del Estado.

Según este mismo autor, el DPO, materializado a través de diferentes registros textuales, incorporará un complejo conjunto de discursos, producciones que serán fundamentales para la organización y construcción del (en este caso naciente) orden normalizado/ normalizante del sistema educativo y del Estado en general. Dichos registros pueden ser textos formales y estrictamente reguladores con un sistema de enunciación codificado y normativo (regulaciones legislativas, decretos, resoluciones, leyes) o presentarse en términos de una serie de enunciados descriptivos que articulan diferentes clases de objetos, conceptos y teorías (conocimiento transformado por la práctica política) que llegan a ser la posición legítima u oficial (libros de textos, prensa educativa especializada, informes).

Desde esta perspectiva, necesariamente, debe producir un principio selectivo por medio del cual se seleccionan contenidos para ser pedagogizados. Esto, a su vez, conlleva una selección de discursos que regulan la transmisión, adquisición y evaluación. En resumen el DPO debe seleccionar tanto los discursos que deben transmitirse como los discursos que regulan los principios de su transmisión-adquisición, o al menos, fijar límites.

Su construcción implica un proceso de recontextualización oficial que ocurre cuando un texto o textos que pertenecen a un discurso específico o discursos específicos son selectivamente desubicados o reubicados e insertos en nuevos textos oficiales. Estos 
nuevos textos incorporan objetos, temas, enunciados y teorías previamente reconocidas e ideológicamente seleccionadas. De esta manera el DPO es portador de concepciones y prescripciones de otros campos del saber y de producción simbólica (Bernstein y Díaz, 1984).

El discurso pedagógico así construido producirá saber oficial sobre el amplio campo de los comportamientos corporales humanos tales como la sexualidad, las formas de vida como los ritmos de sueño y trabajo, la periodicidad de las comidas, el control de las necesidades, las prohibiciones frente a los peligros (Caruso y Dussel, 2000) e incluirá preceptos sobre lo cotidiano, los modos y maneras, los tiempos y los espacios de lo habitual y de las funciones básicas orgánicas. Desde esta perspectiva, como se expresa en la Revista de Educación (1881), la regulación de la vida física, se transforma en la condición sine qua non de la vida intelectual y moral (Rousselot, 1881) y se sintetiza en el concepto de educación integral.

Incluida dentro de los modos de comportamiento transmitidos por la sociedad y atravesado por todas las problemáticas de lo social, la educación alimentaria formará parte de la educación del cuerpo (de esa 'vida física' a regular antes mencionada), conformando parte de la educación integral pregonada por la pedagogía moderna y la ilustración. Sobre ella entonces será posible prescribir en tanto aspecto pulsional corporal y comportamiento a normalizar, a educar, a civilizar. Sobre ella el discurso pedagógico, articulando aspectos cognitivos y estéticos, saberes, percepciones y valores, propondrá un régimen de ingesta para el gobierno de la población infantil y sus familias.

\section{Producir, legitimar y difundir el discurso pedagógico sobre la alimentación: una tarea compartida}

El análisis de los textos contenidos en cada una de las publicaciones parece dar cuenta de una cierta complementariedad entre las revistas en la tarea de difusión de doctrinas, prácticas y otro tipo de novedades pedagógicas entre el magisterio. Tal complementariedad estaría referida a la posibilidad de dar un alcance territorial mayor a cuestiones tales como, por ejemplo, información sobre los planes y programas aprobados por las autoridades educativas nacionales a través del Consejo Nacional de Educación.

El Monitor se ocuparía de informar y crear consensos sobre las políticas educativas o las ideas pedagógicas que las sustentaban entre los docentes de la Capital Federal y los Territorios Nacionales, mientras que La Revista difundiría las noticias y acercaría las discusiones vigentes al conjunto de maestros de la Provincia de Buenos Aires; algunos de los cuales desempeñarían funciones en las escuelas nacionales creadas en territorio 
provincial por efecto de la Ley Lainez y por lo tanto necesitaban estar al tanto de las decisiones en materia educativa del gobierno nacional ${ }^{9}$.

Ambas publicaciones participan del proceso de conformación del discurso pedagógico oficial y, en lo que hace a las ideas pedagógicas referidas a la educación alimentaria permiten vislumbrar dos tipos de tácticas. Una de ellas centrada en trasmitir conocimientos, valores y prácticas sobre alimentación. La otra focalizada en difundir tipos, estilos y formas de organización social deseables a través de la difusión de tales saberes.

\section{Lo que hay que saber sobre la alimentación: los contenidos de la educación alimentaria}

Los temas sobre alimentación que el discurso pedagógico selecciona e incluye en ambas publicaciones parecen orientarse a cuatro cuestiones, que remitirán a diferentes campos simbólicos y del saber:

1. Vincular la alimentación con la higiene antes que con el placer;

2. Fundamentar la dietética en conocimientos científicos;

3. Asociar el orden alimentario al orden moral;

4. Difundir conocimientos, valores y prácticas sobre producción, elaboración y conservación de alimentos

Una de las ideas centrales alrededor de las cuales se desarrolla el discurso sobre la alimentación es que la regulación de la ingesta es una de las estrategias de la higiene, entendida como la ciencia que se ocupa del cuidado de la salud. Los conceptos que orientan las reglas sobre el cuidado de la salud se modifican a medida que se multiplican y ponen en relación teorías que explican el funcionamiento del cuerpo y que permiten aislar los factores que condicionan la conservación de la vida humana.

Desde mediados del 19 las políticas de salud reconocen que las enfermedades pueden ser de origen biológico o hereditario, y en este punto atribuibles al individuo, o de origen ambiental, entendiendo por tal el medio natural y social.

Desde la perspectiva de las ciencias de la naturaleza, en la alimentación parecen confluir tres cuerpos de conocimientos. La higiene en tanto ciencia de conservación de la vida a través del cuidado de la salud; la concepción del cuerpo humano como una

\footnotetext{
${ }^{9}$ La Ley de Educación Común, n. 1.420, tuvo inicialmente tuvo vigencia sobre Capital Federal y Territorios Nacionales en virtud de los alcances que el texto constitucional otorgaba al Estado nacional sobre el tema. El artículo $5^{\circ}$ de la Constitución aprobada en 1853 y luego refrendada por Buenos Aires, delega a las provincias la organización de la educación primaria. La ley n. 4.874 aprobada en 1905 a partir de la iniciativa de Manuel Lainez ampliaría el alcance de la ley anterior autorizando al Consejo Nacional de Educación a abrir escuelas rurales, infantiles, mixtas y elementales en territorios provinciales siempre y cuando las provincias lo solicitasen.
} 
máquina animal que responde a distintos principios (físicos, químicos); y la ciencia moderna de la nutrición, fundada y propagada por médicos, fisiólogos, químicos y higienistas (Gleyse y cols., 2002; Ferrières, 2002).

Las metáforas maquínicas, como explicación del funcionamiento del cuerpo, encuentran eco en las premisas sobre la alimentación. La digestión es una cuestión delicada si se concibe al cuerpo como un sistema de bombas, cañerías y tubos por la cual circulan la comida y los deshechos, además del aire y la sangre, y cuyo recorrido debe ser mantenido sin obstrucciones.

Para su cuidado se aconsejan algunos alimentos y otras prácticas "sumamente ventajosa para la salud (como) la gimnástica - debidamente sistematizada". Con su práctica "facilitase inmensamente la digestión; y por último [...] influye favorablemente sobre la conturbada circulación de la sangre, y sobre el cambio de materia de nuestro cuerpo" (El Monitor, tomo IV, 1884/85, p. 593).

En esta línea los alimentos son concebidos como parte de la energía que permite mantener vivo, funcionando, el cuerpo entendido como máquina a vapor:

Es más todavía lo que se debe a los alimentos. Durante su transformación en sangre y sucesivamente en carne y huesos, se produce el calórico. Casi todo el calor de nuestro cuerpo dimana de los cambios que se verifican en lo que comemos. Cuando se tiene hambre, se siente frío y más cada vez hasta que, no siendo ya posible conservar ningún calor, sobreviene la muerte, más bien de frío que de hambre. Otro bien que de ellos nos resulta, es que nos dan fuerza. Toda la energía necesaria para caminar, estar parado, correr, jugar y estudiar, viene de los alimentos que consumimos. Esta fuerza se produce en nuestro cuerpo, algo así como el fuego determina el vapor de una caldera. (El Monitor, tomo 18, 1902, p. 429/30)

Respecto de la nutrición cabe señalar que la relación entre la medicina y el arte de preparar las comidas estaba ya presente en la medicina premoderna, fundamentada en un principio del cual derivaban todas las prácticas relativas al cuidado del cuerpo. Según aquél todos los seres vivos poseían una naturaleza particular determinada por la combinación de cuatro factores agrupados de a pares: lo caliente y lo frío; lo seco y lo húmedo; en tanto expresiones posibles de los cuatro elementos que constituyen el universo: fuego, aire, tierra y agua.

Una persona se consideraba saludable cuando los elementos de su cuerpo se combinaban de modo equilibrado y estable. La ingesta de comida apropiada era una de las vías para restaurar el equilibrio, tanto ante una situación de enfermedad como luego del esfuerzo del trabajo (Montanari, 2006). 
El lenguaje en que se escribe la dietética premoderna es el de la sensibilidad, de los sentidos; lo placentero y lo saludable están indisolublemente unidos y la elección de alimentos y la preparación de las comidas están estrechamente vinculadas al disfrute y la salud.

Según Montanari (2006) los conocimientos y prácticas ligadas a la cocina son entendidos como parte del arte de la manipulación y combinación inteligente de productos a los efectos de crear comidas balanceadas que no existen previamente en la naturaleza. La intervención de lo culinario será necesaria, para atender la sensibilidad del gusto, satisfacer los placeres de la mesa, mientras simultáneamente se corrige y restaura el equilibrio corporal modelando las cualidades naturales de los productos alimentarios.

Pero a partir de los siglos 17 y 18 la ciencia de la dietética comienza a hablar un lenguaje diferente basado en el análisis químico y la física experimental. Así pues, las prácticas vinculadas a la preparación de los alimentos y la ingesta combinan experiencias cotidianas con postulados científicos, y las prácticas culinarias basadas en el gusto o el sabor de las comidas entran en diálogo y discusión con los valores nutricionales de los alimentos (Montanari, 2006):

yo creo no equivocarme mirando a la Química, como á la Higiene, íntimamente relacionadas con la Economía; para mí son aquellas ciencias, como dos rieles que aunque separados siguen un camino y llegan a un mismo término. Sin investigaciones químicas sería absoluta nuestra ignorancia respecto a los componentes de las materias alimenticias. (Palma, A., 1884, Nociones de economía doméstica, en La Revista, año 3, mayo, p. 491/92).

Los alimentos plásticos son esencialmente constituidos por el carbono, oxígeno, hidrógeno y azoe. En esta serie es necesario presentarlos: El pan, formado de dos elementos distintos, el almidón y el gluten: este último es elástico, pegajoso, y es él quien da al pan su plasticidad. La leche, compuesta e manteca, de suero y de cuajo o queso; el cuajo es el alimento plástico. Los huevos, compuestos de una yema, que es una materia grasa y de la clara o albúmina, que es plástica. La fibrina o sustancia de los músculos y de la carne. Resulta pues, de estas nociones, que una persona debilitada por el trabajo, por la enfermedad o por cualquiera otra circunstancia, conviene el administrarle un régimen de azoe, compuesto de pan, carne, leche o huevos. Las legumbres verdes o frescas, las papas, las habichuelas, los guisantes y sobre todo las zanahorias, los nabos, las coles, etc. no son alimentos confortantes. (C.G., 1881, La ciencia en pequeño, traducido por el Consejo General de Educación, en La Revista, año 1 , agosto, p. 112/13)

La trasmisión de modales y mecanismos de regulación del deseo de comer y de criterios de producción o elección de los alimentos apropiados, es también parte de lo que debe ser enseñado. Educar la elección y conformar el juicio del gusto requiere también civilizar el apetito es decir enseñar a privilegiar lo sano sobre lo sabroso y la moderación 
sobre la gula o glotonería, teniendo en consideración que tal educación supone establecer un mecanismo de control de la ingesta que es, a la vez fisiológico y psicológico (Cappon, citado por Mennell, 2001) ${ }^{10}$.

Como sostiene Rousselot (1881, en La Revista, año 1, diciembre, p. 663) debido a que "el gusto es ávido sin ser ilustrado y la cantidad se sobrepone a la calidad [...] La educación que le conviene es más bien restrictiva":

Lo que es más útil en los primeros años de la infancia[...] es el reglamentar sus comidas de manera que coma siempre a las mismas horas; que coma en proporción a su necesidad: que no coma fuera de sus horas [...]; que no coma nada excitante que lo lleve a comer sin necesidad y que le quite el deseo de los alimentos convenientes a la salud; en fin, que no se le sirvan muchas cosas diferentes, pues la variedad de viandas que vienen unas después de otras, sostienen el apetito después que la verdadera necesidad de comer ha concluido. (Fenelon en Rousselo, 1881, Pedagogía aplicada a la enseñanza primaria en La Revista, año 1, septiembre, p. 242)

Para estos fines El Monitor propone diversos artículos, de corte informativo para los maestros y lecturas para poner a disposición de los escolares que presentan, de diferente modo, consejos sobre alimentación: "La lección sobre el pan" (El Monitor, tomo XIV, 1895, p. 670); "El trigo constituye el alimento más perfecto; ¿Cuántas veces se debe comer por día? La obesidad se combate; Frutas nutritivas" (El Monitor, tomo XVI, 1899/1900, p. 988); Las tendencias ideales del vegetarianismo (El Monitor, tomo 20, 1905, p. 1172/73).

En este aspecto el análisis del discurso pedagógico permite reconocer que la ocupación y la prédica por la alimentación de la población en general exceden la tutela del discurso médico. Si bien el discurso religioso no tiene presencia explícita en estas revistas educacionales ${ }^{11}$ y el fundamento de los diagnósticos toma la palabra de la ciencia, el discurso moral, no estrictamente laico, se solapa con el anterior en el momento de la prescripción.

Los artículos que se orientan a proponer hábitos y pautas alimentarias, comienzan en general construyendo el origen de los males a atender o prevenir en una combinación de conductas morales e higiénicas inadecuadas. Y las soluciones relacionan el discurso médico normativo con el del ascetismo religioso:

\footnotetext{
${ }^{10}$ Según el autor citado, apetito no es lo mismo que hambre. Hambre es un impulso del cuerpo que ocurre en todos los seres humanos en un ciclo razonablemente regular. El apetito de comida es básicamente un estado de la mente, una alerta mental interior de deseo sobre la cual se despliega el hambre. El apetito de un individuo es su deseo e inclinación a comer, su interés en consumir comida. Comer es aquello que una persona hace, apetito es lo que siente mientras lo hace (en Mennell, 2001)

${ }^{11} \mathrm{Y}$ esto es posible de entender en el marco del principio de laicidad prescripto por la ley 1420 y de la preeminencia de las ideas racionalistas de corte positivista a la hora de legitimar las acciones estatales desde el CNE.
} 
El alcoholismo, como razonablemente se ha dicho, no es solamente una enfermedad del individuo, es una enfermedad de familia y que ataca toda la raza. Las familia de los bebedores son generalmente poco numerosas y los individuos que las componen presentan ya desórdenes funcionales, ya lesiones materiales del sistema nervioso, siempre con las consecuencias morales más graves. Los descendientes de los bebedores son por lo general bebedores también; pero frecuentemente tiene predisposiciones fatales al idiotismo y a la locura. Unos nacen idiotas, otros viven intelectualmente hasta cierta edad, fuera de la cual se detienen, incapaces de un progreso ulterior. Habitualmente revelen desde temprano su estado mental por la depravación de sus tendencias, notoriamente por instintos crueles, el robo, etc. Son irritables, violentos. Se muestran refractarios a toda educación, o bien, si han aprendido un estado liberal o una profesión industrial, sus aptitudes desaparecen en un momento dado. La indecisión, la pereza, la necesidad de vagabundear, el oscurecimiento del sentido moral, las apetencias embriagadoras, el debilitamiento intelectual, son los caracteres que más se encuentran en individuos que por último concluyen en un estado mental comparable al idiotismo. Algunos más privilegiados en un principio, gozan de un grado mediano de inteligencia; pero son extravagantes, maniáticos, tienen predisposición a la tristeza. Tarde o temprano, sus facultades se alteran como en los precedentes y experimentan la misma degradación progresiva. (Rousselot 1881, Pedagogía aplicada a la enseñanza primaria, en La Revista, año 1, diciembre, p. 663/64)

El Segundo Congreso Pedagógico Nacional, al cabo de las quince sesiones celebradas en la Biblioteca de Maestros declarará al respecto:

El alcoholismo. Por el doctor Domingo Cabred. Declaraciones aprobadas. Considerando que la vulgarización de las ideas sobre alcoholismo es uno de los medios que deben emplearse para combatir ese flagelo, el congreso expresa el voto de que se dicten en las escuelas frecuentes conferencias sobre dicho tema y se funden sociedades infantiles de templanza. (El Monitor, tomo 17, 1990, p. 809)

La moral y las ciencias pueden ambas trabajar en la eliminación de las prácticas irracionales de consumo que resultan ineficientes y peligrosas; a la vez que la responsabilidad por la enfermedad puede ser colocada sobre las espaldas de los individuos incapaces de moderarse en las pasiones y los apetitos. (Turner, 2001). Es más, el terreno en que ambos discursos mejor se complementan es en la selección de los ramos escolares y los contenidos que para cada uno de ellos se incluyen en los programas.

En ellos las asignaturas que presentan aportes de las ciencias, y conocimientos empíricos sobre producción de alimentos se combinan con otras que se proponen trasmitir valores y principios morales no exentos de connotaciones religiosas como por ejemplo los pecados capitales, tal la gula, la avaricia, la codicia (Gleyse, 2008)

Precisamente en este rubro ambas revistas publican los planes y programas escolares aprobados. En ellos es posible reconocer disciplinas curriculares específicas 
que aportan conocimientos, prácticas y valores que, - por sus justificaciones y por lo que plantean otros registros discursivos que aparecen en las revistas, formarían parte de la educación alimentaria. Unas tienen énfasis teórico y se proponen informar, eventualmente reflexionar - sobre el tema; otras son predominantemente prescriptivas, enfatizando la transmisión de prácticas y procedimientos. En ambos casos contienen una importante carga valorativa:

Ciencias naturales. Tercer Grado [...] Órganos y funciones del cuerpo humano.- Nociones elementales [...] Digestión, dientes, saliva, deglución, tubo digestivo, jugos gástricos [...] Cuarto Grado [...] Nociones de agricultura (para los varones) - Tierra laborable, sus clases [...] Operaciones que requiere la tierra para el cultivo. Cultivo especial de las plantas cuyo consumo es más general. [...]. Quinto grado [...] Movimientos respiratorios [...] - Combustiones orgánicas- Oxígeno y ácido carbónico. Nociones de higiene - Influencia de los agentes naturales en la conservación de la salud - Ventilación [...] Condiciones higiénicas de habitaciones, alimentos, bebidas y vestidos. (El Monitor, tomo VI, 1886/7, p. 398 y sigs. y La Revista, 1887, año 7 diciembre, p. 440-473)

En síntesis la alimentación parece tener desde el discurso pedagógico oficial tiempos, lugares, conocimientos y métodos específicos para su ordenamiento. Parecería que para elegir la comida apropiada en calidad y organizar una ingesta adecuada en cantidad debe conocerse desde crianza de animales y valores nutritivos de las hortalizas hasta la química de la digestión.

Moral y Urbanidad. Segundo Grado. [...] Urbanidad.- Aseo en general.Decencia, elegancia, lujo.- Modo de conducirse en los juegos, comidas, visitas, diversiones.- Buenos modales. Tercer Grado. [...] el cuerpo: Aseo, sobriedad, gimnasia- Perjuicios de la gula y la embriaguez (El Monitor, tomo VI, 1886/7, p. 398 y sigs. ). Física y química. Sexto Grado [...] Elementos de química experimental [...] composición y fabricación del aceite, jabón, velas, almidón, pan, azúcar, leche, vinos, cerveza. (El Monitor, tomo VI, 1886/7, p. 398 y La Revista, 1887, año 7 diciembre, p. 440-473)

La educación alimentaria también requiere conocer las condiciones higiénicas de alimentos y bebidas, para ello es preciso no sólo aprender regulaciones referidas a la ingesta, que se vinculan con la moderación, la evitación de la gula, sino reconocer los componentes y procedimientos de elaboración, para mantener la pureza de los alimentos y evitar o detectar la adulteración:

10. La sal. Su importancia en el organismo y en la cocina. Su composición química. Propiedad de la buena sal. Caracteres para reconocer la falsificada. Su conservación. 11. Procedimientos físico-químicos en la cocina. La fermentación: su importancia en la naturaleza y en la cocina. Fermentación alcohólica; fermento. Vinagre. Cómo evitar la fermentación pútrida en cocina y despensa. (Ema Caprile (1881) Reglamento para el 
examen de maestros y maestras. Escuela normal de maestros de la provincia de Buenos Aires. Programa de los exámenes correspondientes al año escolar 1879, en La Revista, año 1 noviembre, p. 516/17)

\section{Lo que se puede enseñar a través de la educación alimentaria}

Informar sobre técnicas de producción de alimentos, y sobre la división social de tareas en las familias, predicar sobre la pureza de los productos que se adquieren y la calidad de los que se preparan en los hogares y señalar los hábitos saludables son distintos modos a través de los cuales el DPO parece contribuir en la producción y legitimación de un orden social esperado.

Frente a las diferencias en las formas de organización de las familias rurales y urbanas, populares y de elite, las prescripciones curriculares referidas a la alimentación y la higiene individual y social pueden ser interpretadas como parte del proceso de construcción de un modelo familiar que, si bien en los hechos dista mucho de ser capaz de subsumir en su marco las muy diversas prácticas sociales existentes, en términos de imágenes parece capaz de construir como modelo universal a la familia nuclear.

Según Miguez (1999) más precisamente de la 'clase media'; sector social que "se define precisamente a partir de una construcción de imágenes; fruto del proceso de urbanización, de movilidad social, de la diversificación de los consumos, del sincretismo étnico, de la escolarización, de la construcción de la identidad nacional, de la fijación de nuevos estándares de corrección social" (Míguez, 1999, p. 22):

El número de habitantes que puede mantener un país con sus productos
interiores, no depende sólo del arte agrícola, sino del arte de preparar los
alimentos; así, la buena preparación de éstos es de grande importancia
social y merece el más alto interés. Los pueblos salvages (sic) no conoce
ninguna de estas artes: la agricultura y el arte culinario son característicos
de las naciones civilizadas [...]. El grado relativo de civilización de los
pueblos, se conoce en estos tres signos: $1^{\circ}$ La cantidad de jabón,
consumida por habitante, [...]. $2^{\circ}$ La cantidad de papel, invertido en escribir
ó imprimir, [...] $3^{\circ}$ El estado más o menos perfeccionado del arte de la
cocina entre las clases pobres. (Variedades una excentricidad práctica en
La Revista, año 1,1881, p. 330$)^{12}$

Según la nota de La Revista la cuestión culinaria se había elevado a cuestión social para los hombres de estado ingleses que dispusieron se enseñe el arte de la cocina en todas las escuelas primarias de niñas, a fin de que las mujeres de los obreros sepan preparar con economía, aseo y habilidad los alimentos de la familia.

\footnotetext{
${ }^{12}$ Nota tomada del Petite Journal, en el cual Thomas Grimm informa sobre una experiencia educativa realizada en Inglaterra con subsidio de Parlamento.
} 
De esta manera se fundó la Escuela normal nacional de cocina [...] De esta Escuela Normal han salido ya más de tres mil maestras, mugeres (sic) [...] pertenecientes á la clase social de donde salen por lo común las criadas, y que, después de tres meses de aprendizaje culinario, reciben un diploma y luego enviadas por la Escuela Normal á las que existen en los pueblos y aldeas, con el fin de propagar y enseñar su arte. (Variedades una excentricidad práctica, en La Revista, año 1, 1881, p. 331)

En lo que refiere los estados nacional y provincial (en Argentina y Buenos Aires respectivamente) los planes y programas que se aprueban a lo largo del periodo de estudio incluyen asignaturas que contienen conocimientos, valores y prácticas orientadas a la educación alimentaria. Dichas asignaturas contemplan en muchos casos destinatarios específicos. En función de ciertas atribuciones de género naturalizadas, que la escuela incorpora y refuerza, los ramos proponen enseñanzas que asignan saberes particulares al desempeño de roles femeninos y masculinos.

Los conocimientos considerados necesarios para llevar una vida sana y ordenada y hacer una elección racional de la ingesta están en el Plan de Estudios para Escuelas Públicas presentados centralmente en las asignaturas ejercicios intuitivos, ciencias naturales, moral y urbanidad, economía doméstica; con la particularidad que no todos esos ramos están dirigidos a todos los escolares.

En las indicaciones para cuarto grado la asignatura elementos de ciencias naturales contempla contenidos "para los varones" (como por ejemplo nociones de agricultura) mientras que las asignaturas economía doméstica y labores están indicadas "para las niñas".

En el Proyecto de Reducción de los programas vigentes para las escuelas primarias de la Capital Federal, elevado al CNE en marzo de 1901 por el Inspector técnico general Andrés Ferreyra, las asignaturas que refieren conocimientos, valores y prescripciones prácticas referidos al cuidado de la alimentación y del cuerpo están organizadas en cuatro grupos.

Tales grupos de materias se distribuyen a lo largo de los seis años que cubren la escolaridad primaria de modo que para cada grado se indican los saberes y prácticas sobre producción, elaboración y consumo de alimentos que se consideran deben aprender los niños y niñas. El segundo grupo comprende lectura, escritura, idioma nacional, nociones de dibujo, música, labores de mano y nociones de economía doméstica.

Segundo grado [...] Segundo grupo [...] VI Para varones: cuidado de aves de corral - Trabajos sencillos de horticultura y jardinería en huerta escolar. [...] Para mujeres: Utensilios indispensables en la cocina - ComestiblesPreparación de las comidas más comunes y económicas- Cuidados que 
requiere el uso del agua en las casas- Limpieza de la casa [...] cuidado de animales domésticos y plantas. [...] Cuarto grado [...] Segundo grupo [...] VI Para varones Cuidado posible (o estudio) de animales útiles- Excursiones a establecimientos pastoriles, agrícolas e industriales [...] Para mujeres: Utensilios accesorios de cocina - Pastelería y repostería [...] Quinto grado [...] Segundo grupo [...] VI Para varones: Abonos vegetales, animales, mixtos [...] Para mujeres: Utensilios de destilería.- Preparación de bebidas higiénicas [...] Sexto grado [...] Segundo grupo [...] VI. Para los varones: Arboledas, pastizales, eras, viñedos, ingenios. Enfermedades más comunes en los a ganados y sembrados [...] Para mujeres: Utensilios de destilería - Filtros - Preparación de postres y bebidas higiénicas y medicinales. [...] Preparación de medicamentos caseros. (El Monitor, tomo 17,1901 , p. 968)

Al plantear ciertas características y tareas como propias de las mujeres, en sus diferentes roles de mujer, madre y esposa el discurso pedagógico colabora en la construcción de un modelo femenino complementario o necesario del nuevo modelo familiar. Gobernar la sociedad a través de la familia es una de las finalidades estratégicas de estas enseñanzas; para esto será necesario inicialmente constituir a la familia como núcleo organizativo de la vida social, investir a cada uno de sus miembros de roles, responsabilidades y derechos diferenciados para finalmente pasar del gobierno de las familias a un gobierno por las familias (Donzelot, 1998).

Si bien las necesidades de la sociedad nacional argentina no eran idénticas a las de la doblemente revolucionaria francesa que indaga Donzelot ${ }^{13}$, pueden traducirse en esa clave las indicaciones curriculares diferenciadas por sexos y concentradas en las niñas: "Economía doméstica (para las niñas) (cuarto grado). Disposiciones para el gobierno de una casa. Costumbres de orden - Habitaciones, alimentos, ropas, muebles - Gastos e ingresos" (El Monitor, tomo VI, 1886/7, p. 398).

A través de sus lecturas La Revista toma partido respecto del matrimonio como estrategia fundamental para la supervivencia o la mejora de las condiciones de vida de las clases trabajadoras. En ese sentido la enseñanza de saberes diferenciados para niños y niñas se hace eco de las ideas sobre división social del trabajo por género que en este periodo propugnan tanto médicos como políticos. Para la mujer el desarrollo de habilidades domésticas se plantearía no sólo como una ventaja económica para el ahorro sino también como garantía de matrimonio.

La principal vocación de la mujer, es todavía, el matrimonio. Pero cuántas veces no sucede, que un obrero, un empleado de inferior categoría retrocede ante la perspectiva de asociar a su vida una mujer inteligente, atractiva, instruida, pero que no está iniciada en las necesidades caseras,

${ }^{13}$ Cuyo gobierno debía complementar las demandas de estabilidad necesarias para en funcionamiento de la democracia liberal con los esfuerzos por restaurar cierto "orden social alterado" por los efectos de la revolución industrial. 
que no sabe arreglar el menú corriente y que no es capaz de freír un par de huevos y componer la ropa blanca cuando empieza a gastarse [...][produce] como resultado, que se sale del hogar doméstico sin pensar y se vuelve a él sin gran prisa. (Las niñas y la cocina, La Revista, año 9, tomo 18 , mayo 1890 , p. $567-568$ )

La unidad doméstica (familia, hogar, conventillo) podía considerarse como un espacio cotidiano femenino. Siguiendo a Nari (2004) durante la mayor parte del día, los hombres salían a trabajar o a buscar trabajo. Muchos de ellos volvían a almorzar y, por las noches, frecuentaban bares y tabernas. Estas costumbres eran consideradas por las elites letradas como desórdenes familiares de las clases populares y como indicios y/o gérmenes de desórdenes más amplios, sociales y morales.

Será pues responsabilidad de la mujer que el hombre vuelva a su casa; pero esta responsabilidad excedería las cuestiones de clase para instaurarse como cuestiones de género (Nari, 2004):

Hay muchos hogares en los que la mujer no debe contar sino consigo misma para los trabajos domésticos. En otros donde hay facilidad de tener una mucama o una sirvienta para todo servicio, es preciso que ayude a la tarea y que sepa dar instrucciones precisas, pues las agencias de colocaciones están llenas de cocineras que no saben su oficio. Es pues muy conveniente el refuerzo que prestan a la enseñanza femenil esas escuelas de cocina y arreglo doméstico, que no están destinadas precisamente para princesas, sino para la inmensa mayoría de las mujeres. (Las niñas y la cocina, en La Revista, año 9, tomo 18, mayo 1890, p. 567-568)

Respecto de la educación del varón, en los roles de trabajador y ciudadano complementarios a los de la mujer en la división sexual del trabajo que el discurso pedagógico ayudaría a instaurar, los temas de educación alimentaria parecen señalarlo como el destinatario excluyente de las nociones de agricultura y crianza de animales, tareas netamente productivas necesarias para asumir el lugar de hombre proveedor. En este punto, y tomando en consideración la variedad de ocupaciones laborales masculinas existentes, es posible hipotetizar que estos saberes relativos al trabajo productivo y manual tenían un destinatario de clase definido.

\section{Conclusiones}

El análisis del discurso pedagógico oficial construido sobre la educación alimentaria, y difundido a través de estas revistas educacionales ha permitido reconocer la presencia de concepciones provenientes de distintos campos del saber y de producción simbólica. A partir de registros científicos higiénicos y morales el discurso pedagógico seleccionó y construyó un texto oficial en el cual se articulaban prescripciones, descripciones y normas 
que, sin confrontar entre sí, se orientaron a crear y regular los hábitos de alumnos y alumnas en relación a los alimentos y las comidas, su producción y consumo.

Más aún, es posible señalar que tales registros se reforzaban mutuamente prescribiendo lógicas y modelos sexuales y de organización familiar deseables y considerados social y políticamente necesarios en el contexto del cambio de siglo en Argentina. En ese marco, y respecto al tema del que este trabajo se ocupa, las publicaciones muestran consenso y comunidad de perspectivas entre ambas publicaciones.

En este sentido este trabajo aporta evidencia histórica a la hipótesis formulada por Ramos do Ó (2009) según la cual tanto el patrón institucional como las categorías identitarias que la institución escolar pone a circular desde finales del siglo 19, coyuntura que coincide con la autonomización de la ciencia pedagógica y con el arranque de la escolarización masiva de las poblaciones, son, en lo esencial productos e instrumentos de un estilo liberal de gobierno de las poblaciones que no cesa de fusionar la dimensión política con la ética.

\section{Referências}

AISENSTEIN, Angela. Discursos y prácticas para la educación corporal en la escuela argentina: documento líneas de investigación Cohorte 2009. Maestría en Educación, Buenos Aires: Universidad de San Andrés (mimeo), 2010.

AISENSTEIN, Angela. El gusto y la salud en la escuela: trazando líneas en educación alimentaria. Anuario Sahe, n. 11. Buenos Aires: Prometeo, 2010, p. 71-92.

BERNSTEIN, Basil. Pedagogía, control simbólico e identidad: teoría, investigación y crítica. Madrid: Morata, 1998.

BERNSTEIN, Basil; DÍAZ, Mario. Towards a theory of pedagogic discourse en collected original resources in education. Core, v. 8, n. 3, 1994.

CARUSO, Marcelo; DUSSEL, Inês. La invención pedagógica del aula. Buenos Aires: Santillana, 2000.

CARUSO, Marcelo. Latin American independence: education and the invention of new polities. Paedagogica historica, v. 46, n. 4, 2010, p. 409-417.

CONTRERAS, Jesús. Alimentación y cultura: necesidades, gustos y costumbres. Barcelona. Universitat de Barcelona, 1995.

CUCUZA, Rubén. Yo argentino: la construcción de la nación en los libros escolares (18731930). Buenos Aires: Miño y Dávila, 2007.

DE GARINE, Igor. Los aspectos socioculturales de la nutrición. In: CONTRERAS, Jesús (comp.). Alimentación y cultura: necesidades, gustos y costumbres. Barcelona: Universitat de Barcelona, 1995, p. 129-170.

DONZELOT, Jacques. La policía de las familias. Valencia. Pre-textos, 1998. 
DOUGLAS, Mary. Las estructuras de lo culinario. In: CONTRERAS, Jesús. (comp.). Alimentación y cultura: necesidades, gustos y costumbres. Barcelona: Universitat de Barcelona, 1995, p. 171-198.

DOUGLAS, Mary. Pureza y peligro: un análisis de los conceptos de contaminación y tabú. Madrid. Siglo 21, 1973.

DOUGLAS, Mary. Estilos de pensar: ensayos críticos sobre el buen gusto. Madrid: Gedisa, 1998.

FERRIÈRES, Madeleine. Histoire des peurs alimentaires: du moyen Age à l'aube du 20 siecle. Paris: Du Seuil, 2002.

FERRERO, Federico. Un estudio sobre la Revista de Educación: gobierno y estructura del sistema escolar bonaerense (1881-1910). Buenos Aires: Universidad de San Andrés, 2007. Tesis (Maestría en Educación). Escuela de Educación, Universidad de San Andrés.

FOUCAULT, Michel. La gubernamentalidad. In: FOUCAULT, Michel; DONZELOT, Jacques; GRIGNON, Claude; de GAUDEMAR, Jean Paul; MUEL, Francine y CASTEL, Robert. Espacios de poder. Madrid. La Piqueta, 1991.

GIOVINE, Renata. Interpelaciones, representaciones y experiencias de los actores del sistema educativo. El caso de la provincia de Buenos Aires. IV Congreso Nacional y Segundo Internacional de Investigación Educativa, Universidad Nacional del Comahue Facultad de Ciencias de la Educación, 2007.

GLEYSE, Jacques. La fabrication des anges: etudes des contraintes corporelles dans les Manuels de Morale en France, 1880-1964. IVe journées Pierre Guibbert. Montpellier: IUFM de Montpellier, 2008.

MONTANARI, Massimo. Food is culture. New York: Columbia University Press, 2006.

MENNELL, Stephen. On the civilizing of appetite. In: FEATHERSTONE, Mike, HEPWORTH, Mike; TURNER, Bryan S. The body: social process and cultural theory. London: Sage, 2001, p. 126-156.

MESSER, Ellen. Perspectivas antropológicas sobre la dieta. In: CONTRERAS, Jesús (comp.). Alimentación y cultura: necesidades, gustos y costumbres. Barcelona: Universitat de Barcelona, 1995, p. 27-82.

NARI, M. Políticas de maternidad y maternalismo político. Buenos Aires: Biblos, 2004.

NARADOWSKI, Mariano. La utilización de periodizaciones macropolíticas en Historia de la Educación: algunos problemas. In: MARTINEZ BOOM, Alberto; NARODOWSKI, Mariano (comp.). Escuela, historia y poder miradas desde América Latina. Buenos Aires: Novedades Educativas, 1996, p. 149-156.

PINEAU, Pablo. La escuela bárbara: la construcción de un dispositivo de mirada e intervención estética. CONGRESSO IBERO-AMERICANO DE HISTÓRIA DA EDUCAÇÃO, 9, 2009, Buenos Aires. Anais ... Buenos Aires: Universidad de Buenos Aires, 2009.

PINEAU, Pablo; DUSSEL, Ines; CARUSO, Marcelo. La escuela como máquina de educar: tres escritos sobre un proyecto de la modernidad. Buenos Aires. Paidós, 2001.

RAMOS DO Ó, Jorge. A governamentalidade e a historia da escola moderna: outras conexões investigativas. Revista Educação \& Realidade, Porto Alegre: Ufrgs, v. 34, n. 2, 2009, p. 97-117.

RICHTER, Ana Cristina y FERNANDEZ VAZ, Alexandre. Alimentación e higiene en la rutina de la educación infantil: calidad de vida como artificio en la instrucción de las 
conductas y potencialización de los hijos de la nación en Revista Educación Física y Ciencia, v. 10, 2008, p. 77-99.

ROZIN, Paul. Perspectivas psicobiológicas sobre las preferencias y aversiones alimentarias. In: CONTRERAS, Jesús. (comp.) Alimentación y cultura: necesidades, gustos y costumbres. Barcelona: Universitat de Barcelona, 1995, p. 85-110

SCHOO, Susana. Orígenes y desarrollo de la educación secundaria, normal y especial en la Provincia de Buenos Aires: iniciativas provinciales nacionalizadas (1852-1920). Buenos Aires: Universidad de San Andrés, 2009. Tesis (Maestría en Educación). Universidad de San Andrés.

TEDESCO, Juan Carlos. Educación y sociedad en la Argentina (1880-1945). Buenos Aires: Solar, 1993.

TURNER, Bryan. The government of the body: medical regimens and the rationalization of diet. British Journal of Sociology, v. 33, n. 2, 1982, p. 254-269.

TURNER, Bryan. The discourse of diet. In: FEATHERSTONE, Mike, HEPWORTH, Mike; TURNER, Bryan S. The body: social process and cultural theory. London: Sage, 2001, p. 157-169.

ÂNGELA AISENSTEIN é professora na Universidad de San Andrés e na Univesidad Nacional de Luján.

Endereço: M. Pelliza 1349 - Olivos - Provincia de Buenos Aires - CP 1636 Argentina.

E-mail: aaisenstein@udesa.edu.ar.

MARIA EUGENIA CAIRO é maestranda na Universidad de San Andrés.

Endereço: Ricardo Rojas 1310 - Burzaco - Província de Buenos Aires - CP 1852 - Argentina.

E-mail: eugenia cairo@yahoo.com.ar.

Recebido em 10 de março de 2012.

Aceito em 23 de abril de 2012. 